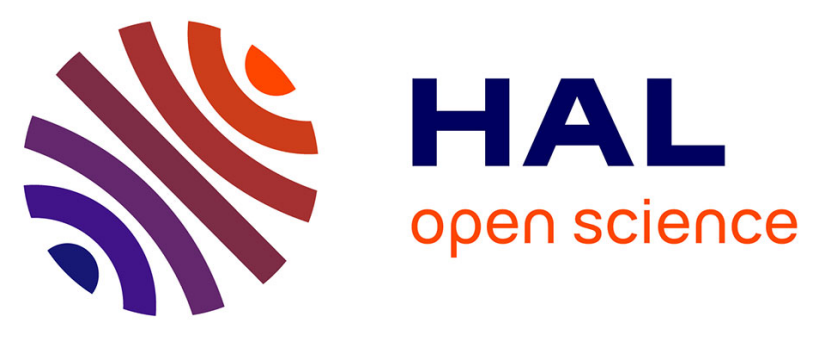

\title{
Optimization of polysaccharides extraction from a wild species of Ornithogalum combining ultrasound and maceration and their anti-oxidant properties
}

Mohammad Kazem Medlej, Batoul Cherri, Ghassan Nasser, François Zaviska, Akram Hijazi, Celine Pochat-Bohatier

\section{To cite this version:}

Mohammad Kazem Medlej, Batoul Cherri, Ghassan Nasser, François Zaviska, Akram Hijazi, et al.. Optimization of polysaccharides extraction from a wild species of Ornithogalum combining ultrasound and maceration and their anti-oxidant properties. International Journal of Biological Macromolecules, 2020, 161, pp.958-968. 10.1016/j.ijbiomac.2020.06.021 . hal-03093126

\author{
HAL Id: hal-03093126 \\ https://hal.science/hal-03093126
}

Submitted on 5 Jan 2021

HAL is a multi-disciplinary open access archive for the deposit and dissemination of scientific research documents, whether they are published or not. The documents may come from teaching and research institutions in France or abroad, or from public or private research centers.
L'archive ouverte pluridisciplinaire HAL, est destinée au dépôt et à la diffusion de documents scientifiques de niveau recherche, publiés ou non, émanant des établissements d'enseignement et de recherche français ou étrangers, des laboratoires publics ou privés. 
1 Optimization of polysaccharides extraction from a wild species of 2 Ornithogalum combining ultrasound and maceration and their anti-

Mohammad Kazem Medlej ${ }^{1,2}$, Batoul Cherry ${ }^{1,2}$, Ghassan Nasser ${ }^{2}$, François Zaviska ${ }^{1}$, Akram Hijazi ${ }^{2}$, Suming Li $^{1}$, Céline Pochat-Bohatier ${ }^{1}$

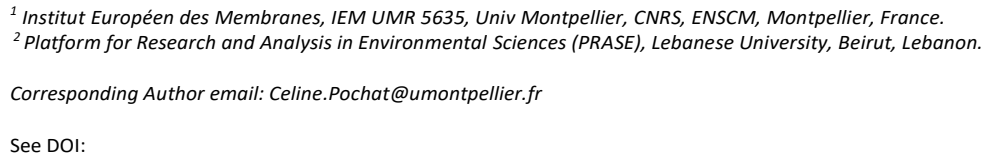

\section{Abstract:}

Polysaccharides were extracted from a wild species of Ornithogalum by using three methods: maceration, ultrasound-assisted extraction, and combination of maceration and ultrasound. Extraction conditions were optimized by using response surface method (RSM) with a central composite design (CCD). Four parameters were considered in the optimization method, i.e. total extraction time, extraction temperature, ratio of water volume to raw material mass, and time percentage of ultrasound treatment in the extraction process. The optimal extraction yield was $81.7 \%, 82.5 \%$ and $85.7 \%$, and the optimal polysaccharides yield was $74.7 \%, 75.7 \%$, and $82.8 \%$ under the optimum conditions of maceration, ultrasound-assisted extraction and combined extraction, respectively. These results indicate that the combination method significantly improves the extraction and polysaccharides yields compared to traditional extraction methods. The combination method also allows reducing the time of ultrasound treatment and thus its adverse effects on polysaccharides. In addition, these results well corroborate with the theoretically predicted values. The NMR $\left({ }^{1} \mathrm{H},{ }^{13} \mathrm{C}, \mathrm{HSQC}, \mathrm{HMBC}\right.$, and COSY) analysis shows that the extract is composed of fructo-polysaccharides with a backbone of $(2 \rightarrow$ 6)-linked $\beta$-d-fructofuranosyl (Fruf)and ( $2 \rightarrow 1$ )-linked $\beta$-d-Fruf branched chains, and terminated with glucose and Fructose residues. The antioxidant activities of the extract were evaluated from ABTS radical scavenging activity, total antioxidant capacity, metal-chelating power and $\beta$ carotene bleaching test. Data show that the extract presents outstanding antioxidant activities.

Keywords: Ultrasonic-assisted extraction; optimization; polysaccharides; anti-oxidant activity.

\section{Introduction}

Synthetic antioxidant compounds such as butylated hydroxyanisole (BHA) are extensively employed as preservatives in pharmaceuticals, cosmetic and food industry. However, some studies have shown that BHA causes adverse effects on cells [1], and thus could have negative 
impact on human health. Therefore, naturally occurring antioxidants have been attracting more and more interest as they actually represent an alternative to synthetic ones.

More than $90 \%$ of the carbohydrate mass in nature is in the form of polysaccharides. Many studies reported that various polysaccharides present remarkable antioxidant activities, and could be used as healthy food additives [2]. Ornithogalum is a genus of perennial plants with various species, including Ornithogalum arabicum, saundersiae, caudatum Ait, dubium, nutans, pyrenaicum, thyrsoides and umbellatum. Polysaccharides extracted from Ornithogalum caudatum Ait present outstanding antioxidant, anticancer, antimicrobial and antiinflammatory activities [3]. They have been used for the treatment of hepatitis, parotitis, and cancers [3]. Ornithogalum billardieri is a non-edible wild plant widespread in Lebanon which could be a potential source of valuable polysaccharides with promising bioactive properties. To the best of our knowledge, this plant has never been studied, so far.

The extraction of polysaccharides represents an important issue for their applications in pharmaceutical and agri-food industries [4]. Maceration is the most commonly used method to extract polysaccharides due to its simplicity. Nevertheless, the major inconvenience of maceration is the low extraction yield [5], long extraction time, and large energy consumption. Ultrasound (US) treatment is a time and energy saving method which is widely used for extraction of various polysaccharides [6]. It allows to reduce the particle size, to disrupt the cell wall, and to improve the mass transfer from solid to liquid phase due to the intense shear forces, thus leading to higher extraction yield [7]. Compared to maceration, US treatment presents many advantages such as reduced extraction time, lower temperature, and in some cases less water consumption [8]. Importantly, US extraction allows to improve the purity of extracted polysaccharides, and their antioxidant activity [9]. However, US treatment can provoke chain cleavage and compositional changes of polysaccharides due to the cavitation effects [9]. Side reactions could also happen and lead to the formation of carbonyl and hydroxyl radical groups.

The aim of this work was to implement and optimize a new extraction process combining both US and maceration in order to improve the extraction yield while reducing the adverse effect of US treatment. Different combinations of maceration and US treatment were tested to extract polysaccharides from Ornithogallum billardieri using the Surface Response Methodology (RSM) applied to an experimental model such as Box-Behnken design (BBD) and central composite design (CCD) [10]. The studied operating parameters include the total duration of the extraction process (time), the extraction temperature, the ratio of added water 
volume to raw material mass, and the time ratio of US treatment in the total process (\% US). The extracted polysaccharides were characterized by using ${ }^{1} \mathrm{H},{ }^{13} \mathrm{C}, \mathrm{HSQC}, \mathrm{HMBC}$, and COSY NMR analysis.

The antioxidant properties of the polysaccharides extracted under optimal conditions were investigated, including ABTS radical scavenging activity, total antioxidant capacity (TCA), metalchelating power, and $\beta$-carotene bleaching test so as to evaluate their potential for applications in the agro-food industry as alternative to synthetic antioxidants.

\section{Experimental}

\subsection{Materials and reagents}

The onion plant Ornithogalum was collected in the region of Bekaa in Lebanon. The plant was carefully washed, cut into small pieces, and freeze dried. The dried plant was manually crushed, and sieved at $0.6 \mathrm{~mm}$ to obtain a homogeneous powder. Sulfuric acid, phenol, 2,2-azino-bis (3ethylbenzothiazoline-6-sulfonic acid) (ABTS), ascorbic acid, potassium peroxydisulfate, sodium phosphate, ammonium molybdate, $\alpha$-tocopherol, iron dichloride, ferrozine, diethylenediamine (EDTA), phenol, anhydrous ethanol, butanol, and chloroform of analytical grade were purchased from Sigma Aldrich, and used as received.

\subsection{Extraction of polysaccharides}

Before extraction, the powder was purified at $70^{\circ} \mathrm{C}$ using a Soxhlet for 2 days with ethanol as solvent. This preliminary step allowed to eliminate all pigments, polyphenols, oligosaccharides, simple oses and amino acids, and also to inactivate enzymes. The powder recovered from the Soxhlet cartridge was vacuum dried overnight at $40^{\circ} \mathrm{C}$, and then crushed and sieved at $0.6 \mathrm{~mm}$. The powder was added in ultrapure water, and homogenized for $30 \mathrm{sec}$ at $3500 \mathrm{rpm}$ in a Speed mixer (Hauschild DAC 150.1 FVZ-K). Extraction then proceeded at a given temperature (25$65^{\circ} \mathrm{C}$ ) for predetermined time periods $(10-60 \mathrm{~min})$. The extraction temperature was controlled $\left( \pm 0.2^{\circ} \mathrm{C}\right)$ using a thermo-cryostat (Vacuo-Temp P, Selecta) and a thermostat cell. The ratio of the water volume to the powder mass varied in the range of 10 to $40 \mathrm{~mL} / \mathrm{g}$. Ultrasound treatment was performed at fixed frequency $(35 \mathrm{KHz})$ and power $(120 \mathrm{~W})$. The time ratio of ultrasound treatment in the total extraction process (\%US) varied between $0 \%$ and $100 \%$. After extraction, the aqueous solution was immediately centrifuged at $6000 \mathrm{rpm}$ for $15 \mathrm{~min}$ three times. The supernatant was lyophilized using a freeze-dryer (Freezone 4.5 Labconco). Finally, the obtained powder was washed with ethanol, and vacuum dried up to constant weight. 
The extraction yield (\%) was calculated using Eq. 1.

Extraction yield $(\%)=[($ Weight of dried product $/$ Weight of crude powder $)] \times 100($ Eq. 1$)$

\subsection{Total carbohydrates content}

The total carbohydrate content (TCC), also known as the polysaccharides yield, was determined according to Dubois method [11]. The method allows to quantify all carbohydrate species, including mono-, di-, oligosaccharides, their methyl derivatives and polysaccharides. A calibration curve was first established from standard glucose solutions at concentrations from 0 to $100 \mu \mathrm{g} / \mathrm{mL}$. $1 \mathrm{~mL}$ of standard solution was added to $5 \mathrm{~mL}$ of concentrated sulfuric acid, followed by addition of $1 \mathrm{~mL}$ of $5 \%(\mathrm{v} / \mathrm{v})$ phenol solution. After $10 \mathrm{~min}$ stirring at $100{ }^{\circ} \mathrm{C}$, the solution was cooled down to room temperature away from light. Finally, the absorbance was measured using a spectrophotometer at $490 \mathrm{~nm}$ ( $\lambda$ max). The absorbance was then plotted against glucose concentration to obtain a calibration curve. The samples are analyzed using the same procedure to obtain the concentration of polysaccharides in samples. The total carbohydrate content (\%) of samples is determined using the following equation:

\section{Total carbohydrate content $(\%)=[($ Weight of polysaccharides $/$ Weight of sample $)] \times 100$}

(Eq. 2)

\subsection{Extraction optimization}

\subsubsection{Single-factor experiments}

A series of preliminary experiments were first performed in order to determine the intervals of the 4 parameters (time, temperature, volume to mass ratio, and US\%), and the range of extraction yield and polysaccharides yield. For each experiment, a single parameter was varied while keeping the others constant: the time was varied from 10 to $60 \mathrm{~min}$, the temperature from $20^{\circ} \mathrm{C}$ to $80^{\circ} \mathrm{C}$, the volume to mass ratio from 10 to $50 \mathrm{~mL} / \mathrm{g}$, and the US\% from 0 to $100 \%$. The results obtained from single factor analysis were used to build a model based on RSM to identify the interactions between parameters.

\subsubsection{Experimental design}

The Surface Response Methodology (RSM) is applied to the central composite design (CCD) for the adaptation of a second order polynomial by the least square technique. Eq. 3 is used to determine the effects of test variables to the searched responses (extraction yield and polysaccharides yield) and the correlation between variables. 


$$
\mathrm{Y}=\beta \kappa_{0} \sum_{i=1}^{4} \beta \kappa_{i} \mathrm{X}_{i}+\sum_{i=1}^{4} \beta \kappa_{i i} X_{i}^{2}+\sum_{i<j=2}^{4} \beta \kappa_{i j} \mathrm{X}_{i} \mathrm{X}_{j}
$$

145

Where $Y$ is the predicted response, $\beta \kappa_{0}$ the intercept, and $\beta$ ki, $\beta$ kii, and $\beta$ kij the coefficients of linearity, quadratic and interaction, respectively. And $X_{i}$ and $X_{j}$ are the coded independent variables. The response function was also related to the coded variables $\left(X_{i}, i=1,2,3\right)$ and $i \neq j$, by a second-degree polynomial using the method of least squares.

The CCD consists of $2^{n}$ factorial points and $2^{n}$ axial points, with $n=$ number of factors studied and Nc central points (replicates in the center of the experimental domain). Four parameters have been taken into account in this study, i.e. Time $X_{1}(\min )$, Temperature $X_{2}\left({ }^{\circ} \mathrm{C}\right)$, Volume $X_{3}$ (volume to mass ratio, $\mathrm{mL} / \mathrm{g}$ ), and US percentage $X_{4}(\%)$. The CCD is thus composed by 16 factorial points, 8 axial points and 5 central points, giving a total of 29 experiments. The axial points are placed at a distance $\alpha=2$ from the center, that makes the design rotatable. The range and levels of the variables are given in Table 1 according to the actual and coded values.

The regression coefficients of individual linear, quadratic and interaction terms were determined using Design-Expert (Version 11) software. They were then used to make statistical calculations, which generate dimensional and contour maps from the regression models.

Table 1 Independent variables and their levels used in the response surface design

\begin{tabular}{lccccc}
\hline \multicolumn{1}{c}{ Coded value } & $\alpha=-2$ & -1 & 0 & +1 & $\alpha=+2$ \\
\hline & \multicolumn{2}{c}{ Real Value } & & & \\
\hline Time (min) & 10 & 22.5 & 35 & 47.5 & 60 \\
Temperature $\left({ }^{\circ} \mathrm{C}\right)$ & 25 & 35 & 45 & 55 & 65 \\
Volume to mass ratio $(\mathrm{mL} / \mathrm{g})$ & 10 & 20 & 30 & 40 & 50 \\
$\%$ US (\%) & 0 & 25 & 50 & 75 & 100 \\
\hline
\end{tabular}

\subsection{Structural characterization}

\subsubsection{Fourier transform infrared (FT-IR)}

FT-IR spectra were recorded using an IR-TF Nicolet IS50 Fourier counter exchange absorption infrared spectrometer (Bruker, Germany) over a range of $400-4000 \mathrm{~cm}^{-1}$. The samples were analyzed as $\mathrm{KBr}$ pellets.

\subsubsection{Size-exclusion chromatography (SEC)}

Size-exclusion chromatography (SEC) was carried out using HPLC (DW-LC1620A) equipped with TSK gel PW5000 + PW3000 columns and refraction index and ultraviolet detectors. The temperature of the columns and detectors was 20 and $35^{\circ} \mathrm{C}$, respectively. A pH 6 phosphate 
buffer at $10 \mathrm{mg} / \mathrm{mL}$ was used as eluent at a flow rate of $1 \mathrm{~mL} / \mathrm{min}$. Calibration was realized using pullulan standards with molar masses from 500 to $25000 \mathrm{Da}$. The results were processed using OmniSEC software.

\subsubsection{NMR Spectroscopy}

${ }^{1} \mathrm{H},{ }^{13} \mathrm{C}, \mathrm{HSQC}, \mathrm{HMBC}$, and COSY NMR spectra were recorded using a Bruker Avance III spectrometer operating at $600 \mathrm{MHz}$ and $150 \mathrm{MHz}$, respectively. $\mathrm{D}_{2} \mathrm{O}$ was used as solvent, and the chemical shifts were expressed in ppm. The spectra were treated using Mestre Nova 12.0.0. software package.

\subsection{Antioxidant activities}

\subsubsection{ABTS radical scavenging activity}

2,2-azino-bis (3-ethylbenzothiazoline-6-sulfonic acid) (ABTS ${ }^{+}$) stock solution was prepared by dissolving $7 \mathrm{mM} \mathrm{ABTS}$ with $2.45 \mathrm{mM} \mathrm{K}_{2} \mathrm{~S}_{2} \mathrm{O}_{8}$ in ultra-pure water, followed by stirring in the dark for $12 \mathrm{~h}$. The solution was diluted with ethanol to obtain an absorbance of $0.7( \pm 0.02)$ at 734 $\mathrm{nm}$ at $30^{\circ} \mathrm{C}$. $0.1 \mathrm{~mL}$ of sample at concentrations from 0.02 to $10 \mathrm{mg} / \mathrm{mL}$ was mixed with $3.9 \mathrm{~mL}$ of the diluted solution of $\mathrm{ABTS}^{+}$. After $20 \mathrm{~min}$ incubation at $30^{\circ} \mathrm{C}$, the absorbance was measured at $734 \mathrm{~nm}$. Ultrapure water was used as blank sample [12], and ascorbic acid as positive control. The ABTS radical scavenging activity was calculated from the following equation:

Where $A_{0}, A_{i e}$ and $A_{e}$ are the absorbance of the blank sample, the positive control, and the samples, respectively.

\subsubsection{Total antioxidant capacity (TCA)}

$100 \mu \mathrm{L}$ of samples at concentrations ranging from 0.025 to $10 \mathrm{mg} / \mathrm{mL}$ were mixed in a tube with $1 \mathrm{~mL}$ of reagent $(0.6 \mathrm{M}$ sulfuric acid, $28 \mathrm{mM}$ sodium phosphate and $4 \mathrm{mM}$ ammonium molybdate). The mixture was incubated at $95^{\circ} \mathrm{C}$ for $90 \mathrm{~min}$. A phosphomolybdenum complex was formed after cooling down to room temperature. Absorbance of the solution was measured at $820 \mathrm{~nm}$. Ultrapure water was used as control [13]. The antioxidant activity is presented in terms of absorption.

\subsubsection{Metal-chelating power}


$100 \mu \mathrm{L}$ of samples at concentrations ranging from 0.2 to $10 \mathrm{mg} / \mathrm{mL}$ were mixed with $50 \mu \mathrm{L}$ of $\mathrm{FeCl}_{2}(2 \mathrm{mM})$, and vigorously stirred for $5 \mathrm{~min}$. Then $100 \mu \mathrm{L}$ of Ferrozine $(5 \mathrm{mM})$ were added together with $2.75 \mathrm{~mL}$ of ultrapure water. After $10 \mathrm{~min}$ at room temperature, the absorbance at $562 \mathrm{~nm}$ was measured.

The blank sample was prepared without addition of ferrozine, while the negative control was prepared without addition of test sample. Ethylenediaminetetraacetic acid (EDTA) was used as positive control [14].

The antioxidant activity was calculated from the following equation:

$$
\text { Antioxidant activity } \%=\left[\left(\mathrm{A}_{\text {control }}-\mathrm{A}_{\text {sample }}\right) / \mathrm{A}_{\text {control }}\right] \times 100
$$

Where $A_{\text {control }}$ and $A_{\text {sample }}$ are the absorbance of the negative control and the sample, respectively.

\subsection{4 $\beta$-carotene bleaching test}

The inhibition of $\beta$-carotene bleaching was evaluated according to the method described by Koleva et al. [15]. $0.5 \mathrm{mg}$ of $\beta$-carotene was dissolved in a mixture of $1 \mathrm{~mL}$ of chloroform, $25 \mu \mathrm{L}$ of linoleic acid and $200 \mu \mathrm{L}$ of Tween-80. The solvent was evaporated in a rotary evaporator at $45^{\circ} \mathrm{C} .100 \mathrm{~mL}$ of ultrapure water was then added to the suspension under stirring. $2.5 \mathrm{~mL}$ of freshly prepared suspension were transferred to a tube containing $0.5 \mathrm{~mL}$ of test samples at concentrations from 0.05 to $5 \mathrm{mg} / \mathrm{mL}$. The mixture is incubated for $2 \mathrm{~h}$ at $50{ }^{\circ} \mathrm{C}$ after homogenization. Ultrapure water was used as control. Absorbance was then measured at a wavelength of $470 \mathrm{~nm}$. The antioxidant activity was calculated from the following equation:

$$
\text { Antioxidant activity }(\%)=\left[1-\left(\mathrm{A}_{0}-\mathrm{A}_{120}\right)_{\text {test }} /\left(\mathrm{A}_{0}-\mathrm{A}_{120}\right)_{\text {control }}\right] \times 100
$$

Where $A_{0}$ and $A_{120}$ are the absorbance of the sample or the control before and after 120 min incubation.

\subsection{Statistical analysis}

The data processing is based on the statistical analysis performed by using the ANOVA Test (Analysis of Variance). A value of $p<0.05$ is considered statistically significant. The data are expressed as mean \pm standard deviation (SD) for three replicates. The lack-of-fit test, F value, determination of coefficient $\left(R^{2}\right)$, adjusted determination coefficient $\left(R_{a d j}{ }^{2}\right)$, coefficient of 
variation (C.V.\%) calculated from Design Expert were used to evaluate the adequacy of the models.

\section{Results and discussion}

245

The challenge of this work is to find a compromise between the positive and negative effects of US extraction and temperature on the extraction and polysaccharides yields, in order to maximize the mass transfer without degrading the quality of the product of interest.

\subsection{Optimization of the extraction}

\subsubsection{Single-factor experiments}

Single-factor experiments were first performed to determine the effect of the 4 parameters, i.e. extraction time, temperature, volume to mass ratio, and US \%, on both of the total extraction yield and polysaccharides yield. The results are presented in Fig. S1 (Supporting information). The same trend is observed in all cases, i.e. an increase of the yields to reach a maximum followed by a decrease.

Based on the results of single factor experiments, it appears that both the extraction and polysaccharides yields are largely dependent on the extraction conditions, and the 4 parameters are inter-dependent. Opposite effects of the parameters are clearly evidenced. In fact, hydrolysis of polysaccharides occurs under harsh conditions. It is thus essential to understand the effect of each parameter on the extraction and polysaccharides yields and the relationship between the parameters by applying the RSM, an efficient statistical technique for optimizing complex processes. The following intervals are selected for the optimization study: time from 22.5 to $47.5 \mathrm{~min}$, temperature from 35 to $55^{\circ} \mathrm{C}$, volume to mass ratio from 20 to 40 $\mathrm{mL} / \mathrm{g}$, and \%US from 25 to $75 \%$.

\subsubsection{RSM statistical analysis and models validity}

Based on the results obtained from single factor analysis, optimization was carried out by using RSM to study the effect of four independent variables $\left[X_{1}\right.$ : time, $X_{2}$ : temperature, $X_{3}$ : volume (ratio of volume to mass), $\mathrm{X}_{4}$ : \%US]. The preliminary results pave the way to determine the interactions between parameters and their influence on the investigated responses. Table 2 shows the matrix of variables in real values and the obtained responses. The predicted response $\mathrm{Y}$ can be correlated to the variables by applying multiple regressions analysis method. The fitting of response functions $Y_{1}$ (extraction yield) and $Y_{2}$ (polysaccharides yield) with the 
experimental data gives a second-order polynomial equation. The analysis of variance table is generated by the Design Expert software (Version 11) used in this study.

The extraction and polysaccharides yields obtained in the 29 experiments vary from 76.2 to $86.1 \%$ and from 70.1 to $82.9 \%$, respectively. Such relatively high values in narrow ranges could be explained by the fact that large amounts of polysaccharides can be easily extracted from the superficial layer of the particles. However, harsher extraction conditions are required to extract species located well inside the particles.

Table 2 RSM centrale composite design and results for extraction yield $\left(Y_{1}\right)$ and polysaccharides yield $\left(Y_{2}\right)$.

\begin{tabular}{ccccccc}
\hline RUN & $\mathrm{X}_{1}$ & $\mathrm{X}_{2}$ & $\mathrm{X}_{3}$ & $\mathrm{X}_{4}$ & $\mathrm{Y}_{1}$ & $\mathrm{Y}_{2}$ \\
\hline 1 & 22.5 & 35 & 20 & 25 & 76.2 & 70.1 \\
2 & 47.5 & 35 & 20 & 25 & 77.2 & 71.0 \\
3 & 22.5 & 55 & 20 & 25 & 76.5 & 71.6 \\
4 & 47.5 & 55 & 20 & 25 & 76.9 & 72.2 \\
5 & 22.5 & 35 & 40 & 25 & 78.7 & 72.2 \\
6 & 47.5 & 35 & 40 & 25 & 83.5 & 77.4 \\
7 & 22.5 & 55 & 40 & 25 & 79.4 & 72.8 \\
8 & 47.5 & 55 & 40 & 25 & 83.0 & 77.3 \\
9 & 22.5 & 35 & 20 & 75 & 81.9 & 75.2 \\
10 & 47.5 & 35 & 20 & 75 & 78.1 & 72.3 \\
11 & 22.5 & 55 & 20 & 75 & 80.0 & 73.4 \\
12 & 47.5 & 55 & 20 & 75 & 76.6 & 71.0 \\
13 & 22.5 & 35 & 40 & 75 & 82.7 & 75.0 \\
14 & 47.5 & 35 & 40 & 75 & 83.3 & 76.5 \\
15 & 22.5 & 55 & 40 & 75 & 78.8 & 72.8 \\
16 & 47.5 & 55 & 40 & 75 & 80.7 & 74.3 \\
17 & 10 & 45 & 30 & 50 & 76.7 & 71.1 \\
18 & 60 & 45 & 30 & 50 & 80.1 & 72.9 \\
19 & 35 & 25 & 30 & 50 & 78.7 & 74.3 \\
20 & 35 & 65 & 30 & 50 & 80.2 & 73.1 \\
21 & 35 & 45 & 10 & 50 & 76.7 & 70.1 \\
22 & 35 & 45 & 50 & 50 & 80.8 & 77.3 \\
23 & 35 & 45 & 30 & 0 & 78.5 & 72.5 \\
24 & 35 & 45 & 30 & 100 & 82.0 & 76.1 \\
25 & 35 & 45 & 30 & 50 & 85.3 & 82.6 \\
26 & 35 & 45 & 30 & 50 & 86.1 & 82.9 \\
27 & 35 & 45 & 30 & 50 & 85.8 & 81.7 \\
28 & 35 & 45 & 30 & 50 & 84.6 & 82.9 \\
29 & 35 & 45 & 30 & 50 & 85.2 & 82.0 \\
\hline & & & & & &
\end{tabular}

In order to highlight the significance of models, statistical indicators such Analysis of Variance (ANOVA) and correlation coefficients $\left(R^{2}\right.$, adjusted $R^{2}$ and predicted $\left.R^{2}\right)$ are determined, as shown in Table 3.

The ANOVA results show that both quadratic models developed for $Y_{1}$ and $Y_{2}$ are highly significant with $F$ values (Fisher coefficient) of 25.1 and 121.3, respectively. Considering also the $p$-values well below $0.05(P<0.0001)$ and the negligible pure errors towards the quadratic model, the lack of fit of these models is insignificant. The correlation coefficient $R^{2}$, adjusted $R^{2}$ and predicted $\mathrm{R}^{2}$ are $0.950,0.912$, and 0.780 for the extraction yield, and are $0.989,0.981$, and 0.959 for the polysaccharides yield, respectively. These values are reasonably close to 1 , 
showing a high degree of correlation. On the other hand, the Adeq. Precision is used to measure the signal to noise ratio, and a ratio above 4 is considered as acceptable. The obtained Adeq Precision is 15.5 and 32.3 for the extraction and polysaccharides yields, respectively, indicating a very high degree of precision and a good reliability of the experimental data. Further analysis of the statistical indicators in Table 3 also shows that the model developed for the polysaccharide yield presents slightly better precision than the one for the extraction yield.

Table 3 Analysis of variance (ANOVA) for Response Surface Quadratic Model of extraction and polysaccharides yields

\begin{tabular}{|c|ccccc|ccccc|}
\hline \multirow{2}{*}{ Source } & \multicolumn{4}{|c|}{ Extraction yield } & \multicolumn{4}{c|}{ Polysaccharides yield } \\
\cline { 2 - 11 } & $\begin{array}{c}\text { Sum of } \\
\text { Squares }\end{array}$ & df & $\begin{array}{c}\text { Mean } \\
\text { Square }\end{array}$ & $\begin{array}{c}F \\
\text { Value }\end{array}$ & p-value & $\begin{array}{c}\text { Sum of } \\
\text { Squares }\end{array}$ & df & $\begin{array}{c}\text { Mean } \\
\text { Square }\end{array}$ & $\begin{array}{c}F \\
\text { Value }\end{array}$ & $\begin{array}{c}p- \\
\text { value }\end{array}$ \\
\hline Model & 263.55 & 12 & 21.96 & 25.13 & $<$ & 448.3 & 12 & 37.36 & 121.3 & 0.0001 \\
Residual & 13.99 & 16 & 0.87 & - & - & 4.93 & 16 & 0.31 & - & - \\
Lack of Fit & 12.65 & 12 & 1.05 & 3.15 & 0.1388 & 3.72 & 12 & 0.31 & 1.02 & 0.5444 \\
Pure Error & 1.34 & 4 & 0.33 & - & - & 1.21 & 4 & 0.3 & - & - \\
C.V.\% & 1.16 & & & & & 0.74 & & & & \\
\hline
\end{tabular}

\subsubsection{Regression equations and significant terms analysis}

ANOVA tests are performed to evidence the significance of the studied parameters on the responses. The insignificant terms are removed in order to refine the developed models. As shown in Fig. 1, the experimental data are scattered around the theoretical line (Predicted vs Actual values), which indicates that the results obtained from the model well agree with the experimental data.
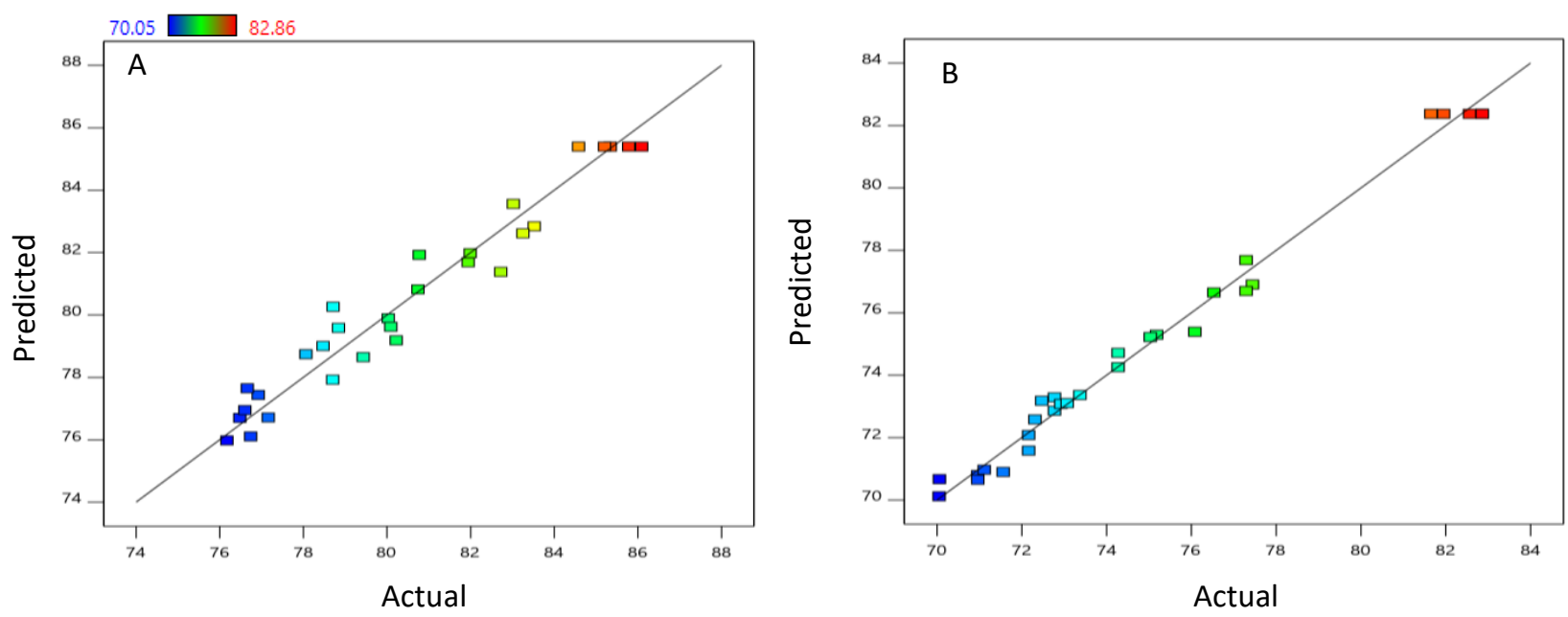

Fig. 1 Diagnostic plot (predicted vs actual values) for the adequacy of proposed model for extraction yield (A) and polysaccharides yield (B).

The simplified equations for the extraction yield $Y_{1}$ and polysaccharides yield $Y_{2}$ are presented in terms of coded factor as follows: 
$Y_{1}=85.40+0.49 X_{1}-0.27 X_{2}+1.46 X_{3}+0.74 X_{4}+1.04 X_{1} X_{3}-0.92 X_{1} X_{4}-0.63 X_{2} X_{4}-0.56 X_{3} X_{4}-1.69$

$\mathrm{X}_{1}^{2}-1.42 \mathrm{X}_{2}^{2}-1.60 \mathrm{X}_{3}^{2}-1.23 \mathrm{X}_{4}^{2}$

$Y_{2}=82.38+0.53 X_{1}-0.29 X_{2}+1.51 X_{3}+0.55 X_{4}+1.04 X_{1} X_{3}-0.85 X_{1} X_{4}-0.68 X_{2} X_{4}-0.51 X_{3} X_{4}-$

$2.59 X_{1}^{2}-2.17 X_{2}^{2}-2.17 X_{3}^{2}-2.02 X_{4}^{2}$

320

321

322

323

324

325

326

327

328

329

330

331

332

333

334

335

336

337

338

339

340

341

342

343

The coefficients associated to the parameters or the interactions give a precise idea of how they affect the corresponding responses (positively or negatively). Firstly, it appears that the effect of the parameters and interactions follow the same trend for both $Y_{1}$ and $Y_{2}$. Regarding the coefficients, the ratio of volume to mass $\left(X_{3}\right)$ is the most important factor affecting the extraction process, followed by the US $\%\left(X_{4}\right)$ and the extraction time $\left(X_{1}\right)$. The extraction temperature $\left(X_{2}\right)$ is the less significant parameter. It is well known that temperature generally enhances the polysaccharide solubility and mass transfer, but it is also a destructive factor as the US treatment. Raza et al. reported similar adverse effect of temperature [16]. Thus, opposite effects could happen, minimizing the overall effect on the response. Regarding the interactions, the most important one is referred to the synergistic (positive) effect between the treatment time and the volume to mass ratio $\left(X_{1} X_{3}\right)$ which enhances the polysaccharide extraction, in agreement with literature [16]. Indeed, both factors $\left(X_{1}\right.$ and $\left.X_{3}\right)$ are nondestructive parameters. When the ratio of volume to mass is higher, the overall driving force is higher, thus accentuating the effect of the extraction time.

It is also noticed that US has systematically a negative effect when combined with another factor. This means that US has a positive effect under mild extraction conditions, i.e. all other parameters at low level. But as soon as the extraction conditions become harsher, the destructive effect becomes predominant. This phenomenon is more accentuated with the treatment time $\left(X_{1} X_{4}\right)$, which makes sense as US (percentage of $\left.X_{1}\right)$ is directly dependent on the treatment time.

\subsubsection{Response surface analysis and optimization}

The two responses $Y_{1}$ and $Y_{2}$ follow the same trend as indicated above. Therefore, the same effects and interactions of the parameters are expected for both responses. Only the polysaccharides yield was investigated by using the Design-Expert to construct a threedimensional surface according to Eq. 8. The RSM was used to determine the relationship between extraction parameters and responses, as shown in Fig. 2. Two variables are continuously varied while keeping the two others constant. 
350

351

352

353

354

355

356

357

358

359

360

361

362

363

364

365

366

367

368

369

370

371

372

373

374

375

376

377

Fig. $2 \mathrm{~A}$ presents the effect of interaction between volume to mass ratio and extraction time on the polysaccharides yield, while the extraction temperature is fixed at $35^{\circ} \mathrm{C}$ and US\% at $25 \%$. The highest polysaccharides yield of $78.2 \%$ is observed at $40 \mathrm{~min}$ and $36 \mathrm{~mL} / \mathrm{g}$. In fact, the increase of volume to mass ratio results in increase of the polysaccharides yield. But in the meantime, the extraction time required to obtain the maximum of polysaccharides increases due to the dilution effect [17].

Fig. 2B presents the effect of temperature and US \% while keeping the time fixed at 22.5 min and volume to mass ratio at $20 \mathrm{~mL} / \mathrm{g}$. At low temperature $\left(35^{\circ} \mathrm{C}\right)$, the polysaccharides yield increases from 70.1 to $75.3 \%$ with US\% increasing from 25 to 75 . It appears that there is little destructive effect of US under mild extraction conditions.

Fig. $2 \mathrm{C}$ presents the effect of volume to mass ratio and US\% on polysaccharide yield at fixed time $(47.5 \mathrm{~min})$ and temperature $\left(55^{\circ} \mathrm{C}\right)$. Under these harsh conditions, the US treatment above $42 \%$ leads to a decrease by $8.2 \%$ of the maximum of polysaccharides yield.

Fig. 2D presents the effect of time and US\% on polysaccharides yield while keeping the volume to mass ratio at $30 \mathrm{~mL} / \mathrm{g}$ and the temperature at $45^{\circ} \mathrm{C}$ (level 0 ). A remarkable increase of the polysaccharides yield is detected with extraction time. However, an extraction time longer than 37.1 min leads to decrease of the polysaccharides yield. In fact, prolonged extraction time could lead to cleavage of polysaccharide chains, resulting in decrease of the polysaccharides yield [18]. The polysaccharides yield increases with the increase of US\% up to a maximum at $51.7 \%$. Beyond, a decrease of the polysaccharides yield is observed. Additionally, the extraction time required to obtain the maximum of polysaccharides yield becomes shorter with increase of US\%. These results evidence the effect of the main parameters and their interactions, which allows to better understand the extraction process. In particular, it is clearly shown that the US is definitely promoter of extraction because of improved mass transfer. But US also has a destructive effect in combination with other parameters such as high extraction temperature. 

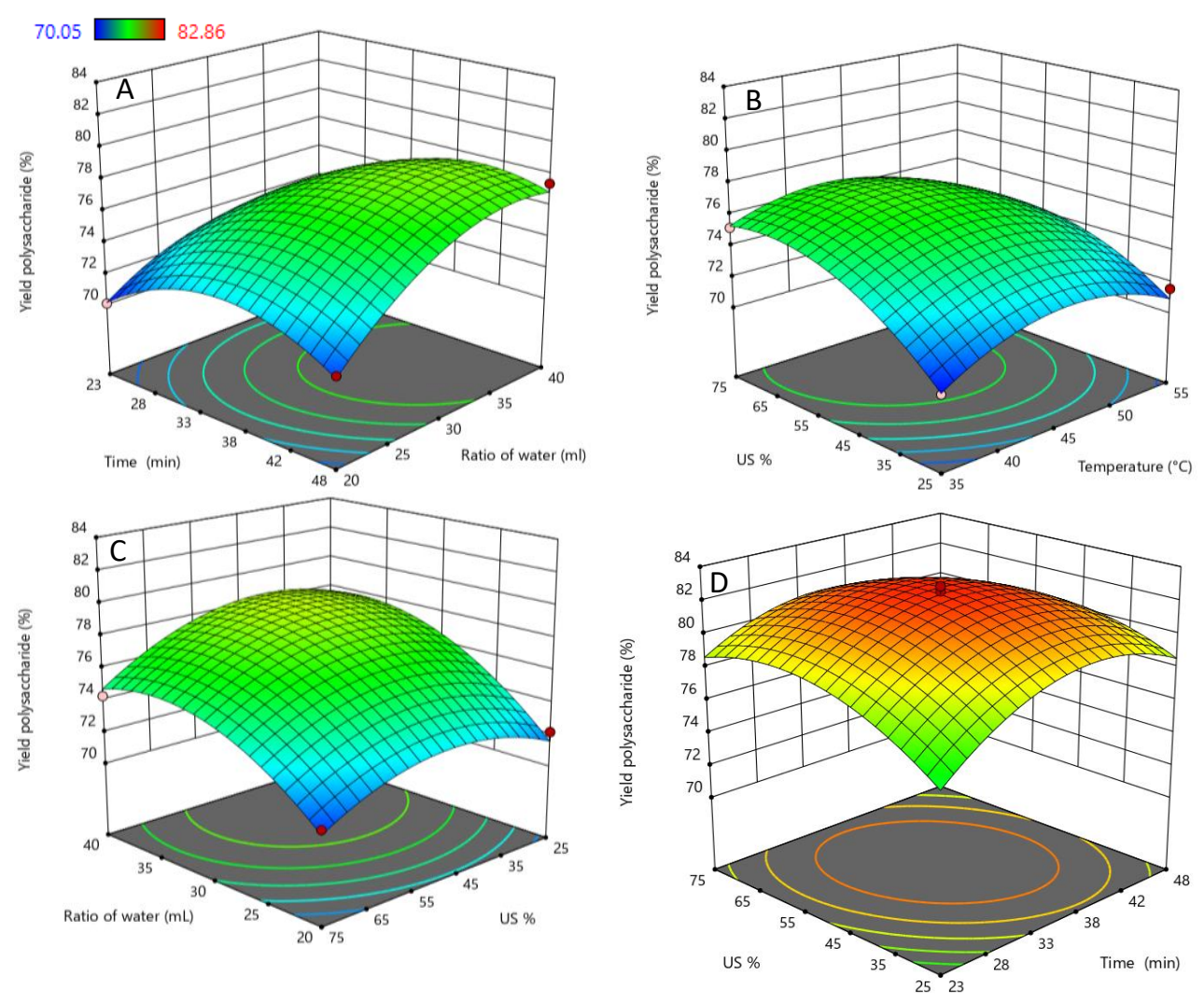

Fig. 2 3D response surface plots showing the interactive effects of $(A)$ time and volume to mass ratio at $(-1,-1)$, (B) temperature and US\% at $(-1,-1)$, (C) volume to mass ratio and US $\%$ at $(+1,+1)$, and (D) time and US $\%$ at $(0,0)$.

\subsubsection{Validation of predictive models}

The optimal extraction conditions to obtain the highest extraction and polysaccharides yields are given below: time $(38.5,37.1 \mathrm{~min})$, temperature $\left(43.5,44.0^{\circ} \mathrm{C}\right)$, volume to mass ratio $(35.4$, $33.8 \mathrm{ml} / \mathrm{g})$, and US\% $(52.8,51.7 \%)$. Under these conditions, the theoretical extraction and polysaccharides yields are $85.9 \%$ and $82.7 \%$ respectively.

Extraction was repeated three times under the optimal conditions in order to validate the two models for the extraction and polysaccharides yields. The obtained extraction yield is $85.7 \pm$ $0.2 \%$, and the polysaccharides yield is $82.8 \pm 0.1 \%$. These values are very close to the theoretical ones, thus validating the models for evaluation of the effects of the 4 parameters on the extraction and polysaccharides yields.

In order to evidence the ambivalent effects of the US treatment, additional experiments were conducted at either $0 \%$ US (only maceration) or $100 \%$ US. The experimental results are then compared with the theoretical values obtained from the developed models, as shown in Table 4. For the extraction yield, the first test was performed at $0 \%$ US under the predicted optimal conditions (time: $47.49 \mathrm{~min}$; temperature: $47.84^{\circ} \mathrm{C}$; volume to mass ratio: $40 \mathrm{~mL} / \mathrm{g}$ ), giving a maximum predicted extraction yield of $81.7 \%$. The average extraction yield of three repeated experiments at $0 \%$ US was $81.7 \% \pm 0.1 \%$. The second test was performed at $100 \%$ US, which 
allowed to obtain a maximum predicted extraction yield of $82.7 \%$ under the optimal conditions (time: $30.03 \mathrm{~min}$; temperature: $39.62^{\circ} \mathrm{C}$; volume to mass ratio: $30.02 \mathrm{~mL} / \mathrm{g}$ ). The average extraction yield of three repeated experiments at $100 \%$ US was $82.5 \% \pm 0.1 \%$.

In the case of the polysaccharides yield, at 0\% US the maximum predicted polysaccharides yield was $74.8 \%$ under the optimum conditions (time: $42.12 \mathrm{~min}$; temperature: $47.1^{\circ} \mathrm{C}$; volume to mass ratio: $37.2 \mathrm{~mL} / \mathrm{g}$ ). The average yield of three repeated experiments was $74.7 \pm 0.1 \%$. At $100 \%$ US, the maximum predicted polysaccharides yield was $75.8 \%$ under the optimum conditions (time: $32.41 \mathrm{~min}$; temperature: $41.2^{\circ} \mathrm{C}$; volume to mass ratio: $30.8 \mathrm{ml} / \mathrm{g}$ ). The average polysaccharides yield of three repeated experiments was $75.7 \% \pm 0.1 \%$.

The model was then used to achieve the yield maximum under the mildest conditions. $A$ theoretical extraction yield of $83.0 \%$ was predicted with the following conditions: $23.7 \mathrm{~min}$, $39^{\circ} \mathrm{C}, 22.6 \mathrm{~mL} / \mathrm{g}$ and $69.5 \%$ US. The experiences gave an average yield of $83.0 \pm 0.1 \%$, which is nearly the same as the predicted value. This technique leads to significant decrease in time by $6.3 \mathrm{~min}$, temperature by $0.7^{\circ} \mathrm{C}$ and volume to mass ratio by $7.4 \mathrm{~mL} / \mathrm{g}$, while a small increase in extraction yield by $0.4 \%$ is obtained as compared to $100 \%$ US extraction (Table 4). Similarly, an optimal polysaccharide yield of $76.3 \%$ is predicted under the following conditions: $23.1 \mathrm{~min}$, $35^{\circ} \mathrm{C}, 21.3 \mathrm{~mL} / \mathrm{g}$ and $65.3 \%$ US. Extraction performed three times under these conditions gave a polysaccharide yield of $76.1 \% \pm 0.1 \%$. Comparison between the combined system and extraction with $100 \%$ US indicates that the former allows a small increase in yield by $0.4 \%$, while decreasing significantly the time, temperature, and volume to mass ratio by $9.3 \mathrm{~min}$, $6.2^{\circ} \mathrm{C}$, and $9.5 \mathrm{~mL} / \mathrm{g}$, respectively (Table 4 ).

It is also of interest to compare the purity of the extract which is defined as the ratio of the polysaccharides yield to the total extraction yield. Under the optimum conditions of maceration, $100 \%$ US, and combined system, the purity of polysaccharides was $91.4 \pm 0.1 \%$, $91.8 \pm 0.2 \%$, and $96.6 \% \pm 0.1 \%$, respectively. Thus, the combination of maceration and US allows improving the purity of the extract.

Chen et al. reported an optimized polysaccharide yield of $36.8 \pm 1.8 \%$ for extraction from Ornithogalum Caudatum Ait under the following conditions: frequency $40 \mathrm{kHz}$, temperature 60 ${ }^{\circ} \mathrm{C}$, extraction time $60 \mathrm{~min}$, ultrasound power $500 \mathrm{~W}$, solvent to raw material $30 \mathrm{~mL} / \mathrm{g}, 3$ times extraction [26]. The yields obtained in the present study (frequency $35 \mathrm{kHz}$, ultrasound power $120 \mathrm{~W}$ ) are significantly higher, in agreement with successful optimization of ultrasound assisted extraction. The combined extraction process allowed to reduce the sonication time, and thus to prevent excessive polysaccharide degradation. 
Table 4 Comparison of parameters, predicted and experimental values for optimization of extraction yield (Y1) and polysaccharides yield ( $\mathrm{Y} 2$ ) by mixed system, maceration and US treatment

\begin{tabular}{|c|c|c|c|c|c|}
\hline $\begin{array}{c}X_{1} \\
(\min )\end{array}$ & $\begin{array}{c}\mathrm{X}_{2} \\
\left({ }^{\circ} \mathrm{C}\right)\end{array}$ & $\begin{array}{c}X_{3} \\
(\mathrm{~mL} / \mathrm{g})\end{array}$ & $\begin{array}{l}X_{4} \\
(\%)\end{array}$ & $\begin{array}{c}\text { Predicted } \\
(\%)\end{array}$ & $\begin{array}{c}\text { Experimental } \\
(\%)\end{array}$ \\
\hline \multicolumn{6}{|c|}{ Y1 } \\
\hline 38.5 & 43.5 & 35.3 & 52.8 & 85.9 & $85.7 \pm 0.2 \%$ \\
\hline 47.5 & 47.8 & 40 & 0 & 81.7 & $81.7 \pm 0.1 \%$ \\
\hline 30.0 & 39.6 & 30.0 & 100 & 82.6 & $82.5 \pm 0.1 \%$ \\
\hline 23.7 & 38.9 & 22.6 & 69.5 & 83.0 & $83.0 \pm 0.1 \%$ \\
\hline \multicolumn{6}{|c|}{ Y2 } \\
\hline 37.1 & 44.2 & 33.8 & 51.7 & 82.7 & $82.8 \pm 0.1 \%$ \\
\hline 42.1 & 47.1 & 37.1 & 0 & 74.8 & $74.7 \pm 0.1 \%$ \\
\hline 32.4 & 41.2 & 30.8 & 100 & 75.8 & $75.7 \pm 0.1 \%$ \\
\hline 23.1 & 35 & 21.3 & 65.3 & 76.3 & $76.1 \pm 0.1 \%$ \\
\hline
\end{tabular}

The extract with optimal purity of polysaccharides, namely OP\%US, was obtained under the following conditions: time $37.1 \mathrm{~min}$, temperature $44.2^{\circ} \mathrm{C}$, volume to mass ratio $33.8 \mathrm{~mL} / \mathrm{g}$, and US\% $51.7 \%$. OP\%US was used for further analyses.

\subsection{Structural characterization}

\subsubsection{FT-IR analysis}

The FT-IR spectrum of OP\%US is presented in Fig. S2 (Supporting information). The large band at $3405 \mathrm{~cm}^{-1}$ is assigned to the stretching vibration of $\mathrm{O}-\mathrm{H}$ groups, and the band at 2941 and $2896 \mathrm{~cm}^{-1}$ were assigned to the stretching of $-\mathrm{CH}_{3}$ and $-\mathrm{CH}_{2}$ groups respectively. The band in the range of $1420 \mathrm{~cm}^{-1}$ belongs to the deformation vibration of $\mathrm{C}-\mathrm{H}$ bond. The monosaccharide of OP\%US has pyranose rings as evidenced by two strong absorption bands of $\mathrm{C}-\mathrm{O}-\mathrm{C}$ asymmetric stretching at $1132 \mathrm{~cm}^{-1}$ and $1027 \mathrm{~cm}^{-1}$. The band at $931.2 \mathrm{~cm}^{-1} \mathrm{~s}$ attributed to the symmetric stretching of furan rings. And the band detected at $599 \mathrm{~cm}^{-1}$ is assigned to the presence of the skeletal $-\mathrm{CH}_{2}$ of pyranose rings. An $\alpha$-configuration in the polysaccharide is confirmed by the presence of characteristic absorptions at $818 \mathrm{~cm}^{-1}$.Therefore, OP\%US was an $\alpha$-configuration polysaccharide and consisted of pyranoside and funanside rings $[19,20]$.

\subsubsection{Size-exclusion chromatography analysis}

From the results obtained in the RSM experiments, it appears that chain cleavage of polysaccharides occurred to some extent during extraction. GPC analysis was then performed for the corners of the design expert model in order to figure out the effect of extraction parameters on the molar masses of the extracts, as summarized in Table 5 . The effect of extraction time is evidenced from the comparison between runs 17 and 18 since different extraction times were used while keeping the three other parameters constant. Similarly, the effect of extraction temperature and US \% is evidenced from the comparison between runs 19 and 20 , and runs 23 and 24 , respectively. 
462

463

464

465

466

467

468

469

470

471

472

473

474

475

476

477

478

479

480

481

482

483

484

485

486

487

488

489

490

491

492

In runs 17 and 18, the average molar mass (Mw) decreases from 5190 to 2940 Da when the extraction time is raised from 10 to $60 \mathrm{~min}$ at fixed temperature $\left(45^{\circ} \mathrm{C}\right)$, volume to mass ratio $(30 \mathrm{~mL} / \mathrm{g})$, and US\% (50\%). In the meantime, the dispersity ( $\theta=\mathrm{Mw} / \mathrm{Mn}$ ) slightly increases from 1.41 to 1.53 . The negative effect of ultrasonic time on the molar mass of schizophyllan has been also reported by Zhong et al. [21].

In runs 19 and 20 , with the extraction temperature increasing from 25 to $65^{\circ} \mathrm{C}$, the $\mathrm{Mw}$ of the extract slightly decreases from 3180 to $2830 \mathrm{Da}$, whereas the dispersity remains almost unchanged.

Finally, in runs 23 and 24, with increase of US treatment from $0 \%$ to $100 \%$, the Mw slightly decreases from 3350 to $3030 \mathrm{Da}$, and the dispersity remains almost unchanged. These results suggest that long extraction time, high extraction temperature, and ultrasound treatment provoke chain cleavage and molar mass decrease of the extract, which could affect the extract yield as shown in the RSM experiments.

Table 5 Molar mass (Mw) and dispersity $(\bigoplus)$ of the extract obtained in selected runs

\begin{tabular}{ccccccc}
\hline Run & $\begin{array}{c}\text { Time } \\
(\mathrm{min})\end{array}$ & $\begin{array}{c}\text { Temperature } \\
\left({ }^{\circ} \mathrm{C}\right)\end{array}$ & $\begin{array}{c}\% \text { US } \\
(\%)\end{array}$ & $\begin{array}{c}\text { Ratio } \\
(\mathrm{mL} / \mathrm{g})\end{array}$ & $\begin{array}{c}\mathrm{Mw} \\
(\mathrm{Da})\end{array}$ & $\oplus$ \\
\hline 17 & 10 & 45 & 50 & 30 & 5190 & 1.41 \\
18 & 60 & 45 & 50 & 30 & 2940 & 1.53 \\
19 & 35 & 25 & 50 & 30 & 3180 & 1.49 \\
20 & 35 & 65 & 50 & 30 & 2830 & 1.52 \\
23 & 35 & 45 & 0 & 30 & 3350 & 1.50 \\
24 & 35 & 45 & 100 & 30 & 3030 & 1.52 \\
\hline
\end{tabular}

\subsubsection{NMR Spectroscopy}

Various NMR analyses, including ${ }^{1} \mathrm{H},{ }^{13} \mathrm{C}, \mathrm{HSQC}, \mathrm{HMBC}$, and COSY NMR were performed to determine the composition of the extract.

The ${ }^{13} \mathrm{C}$ NMR in Fig. 3A presents signals in the region of 59.0-61.48, 73.3-75.15, 57.3-77.77, 79.05-82.5, and 103.0-104.2 related to the $C_{1}, C_{6}, C_{4}, C_{3}, C_{5}$, and $C_{2}$ of fructose rings respectively. Additionally, four anomeric $C_{2}$ carbon signals are detected $(103.11,103.76,103.90$, and 103.95 ppm), which indicates the presence of four fructose residues, i.e. $\beta$-d-Fruf- $(2 \rightarrow, \rightarrow 1,6)-\beta-d-$ Fruf- $(2 \rightarrow, \rightarrow 1) \beta$-d-Fruf- $(2 \rightarrow$, and $\rightarrow 2) \beta$-d-Fruf- $(6 \rightarrow$ respectively respectively designated as residues $B, C, D$, and $E$.

Fig. 3B presents the ${ }^{1} \mathrm{H}$ NMR spectrum of the extract. Small signals are detected around 2.4, 2.5 and $2.7 \mathrm{ppm}$, which could be assigned to the presence of amino acids, carboxylic acids, alcohols or phenols, in agreement with literature [22]. The signals at 3.8-3.7, 4.27, 4.13, 3.89, and 3.86- 
493

494

495

496

497

498

499

500

501

502

503

504

505

506

507

508

509

510

511

512

513

514

515

516

517

$3.68 \mathrm{ppm}$ belong to the protons of fructose ring from $\mathrm{H}_{1}$ to $\mathrm{H}_{6}$, whereas the signals at 3.50, 3.59, and $3.98 \mathrm{ppm}$ are attributed to the protons $\mathrm{H}_{4}, \mathrm{H}_{2}$ and $\mathrm{H}_{5}$ of glucose, respectively. The signal at $5.45 \mathrm{ppm}$ indicates the presence of a proton on $\alpha$ of anomeric carbon. This proton belongs to glucose named as residue $A$ as fructo-ketose has no anomeric proton, which is in agreement with FTIR results [23]. The chemical shifts for $\mathrm{H}_{1}, \mathrm{H}_{3}, \mathrm{H}_{4}$ of residues $B, C, D$, and $E$ of fructose presented in Table 6 were determined from ${ }^{1} \mathrm{H}, \mathrm{HSQC},{ }^{1} \mathrm{H}-{ }^{1} \mathrm{H}$ COSY spectra, and the assignment of $\mathrm{H}_{5}$ and $\mathrm{H}_{6}$ realized from the ${ }^{1} \mathrm{H}-{ }^{1} \mathrm{H}$ COSY and $\mathrm{HMBC}$ spectra.

The HQSC spectrum fig. $3 C$ of the extract presents typical signals at 81.08/3.9 and 80.28/3.98 ppm assigned to the $C_{5}$ of $\left.\rightarrow 2\right) \beta-d-F r u-(1 \rightarrow$ and $\rightarrow 2) \beta$-d-Fru- $(6 \rightarrow$, respectively [24]. The signals of $H_{1}, H_{3}, H_{4}, H_{5}$ and $H_{6}$ of fructose are related to the carbon signals at $60.46,76.62$, $74.46,81.08$, and 63.37 ppm, respectively. Meanwhile, the signals at 3.51, 3.59, 3.79, 3.98, 3.93.7, and 5.45 ppm are linked to $C_{4} 69.32, C_{2} 71.18, C_{3} 72.52, C_{5} 71.67, C_{6} 61.9$, and $C_{1}$ of anomeric carbon 92.15 ppm for glucopyranose ring, respectively [25].

The sequence among residues and the linkage sites were achieved using the HMBC spectrum which provides signals correlations between protons and carbons (Fig. 3D). The various signals are assigned as follows. $C_{2}(103.11 \mathrm{ppm})$ for residue $B$ and $H_{1}(3.91 \mathrm{ppm})$ for residue $D$ $\left(\mathrm{BC}_{2} / \mathrm{DH}_{1}\right)$, suggesting that $\mathrm{C}_{2}$ of residue $\mathrm{B}$ is linked to $\mathrm{O}-1$ of residue $\mathrm{D}$. Similarly, cross signals at $103.11 / 3.89 \mathrm{ppm}$ are assigned to $\mathrm{BC}_{2} / \mathrm{EH}_{6}, 103.76 / 3.73 \mathrm{ppm}$ to $\mathrm{CC}_{2} / \mathrm{CH}_{6}, 103.93 / 3.71 \mathrm{ppm}$ to $\mathrm{DC}_{2} / \mathrm{CH}_{1}, 103.93 / 3.91 \mathrm{ppm}$ to $\mathrm{DC}_{2} / \mathrm{DH}_{1}, 103.95 / 3.73 \mathrm{ppm}$ to $\mathrm{EC}_{2} / \mathrm{CH}_{6}$, and $103.96 / 3.89 \mathrm{ppm}$ to $\mathrm{EC}_{2} / \mathrm{EH}_{6}$. Thus, the results obtained from $\mathrm{HMBC}$ suggest the following sequences: $\mathrm{BC}_{2} \rightarrow \mathrm{EO}_{6}$, $\mathrm{CC}_{2} \rightarrow \mathrm{CO}_{6}, \mathrm{DC}_{2} \rightarrow \mathrm{CO}_{1}, \mathrm{DC}_{2} \rightarrow \mathrm{DO}_{1}, \mathrm{EC}_{2} \rightarrow \mathrm{CO}_{6}$, and $\mathrm{EC}_{2} \rightarrow \mathrm{EO}_{6}$. Finally, the COSY spectrum in Fig. $3 S$ (Supporting information) shows cross signals between $\mathrm{H}_{3} / \mathrm{H}_{4} ; \mathrm{H}_{4} / \mathrm{H}_{5}$ and $\mathrm{H}_{5} / \mathrm{H}_{6}$, in agreement with literature [26].

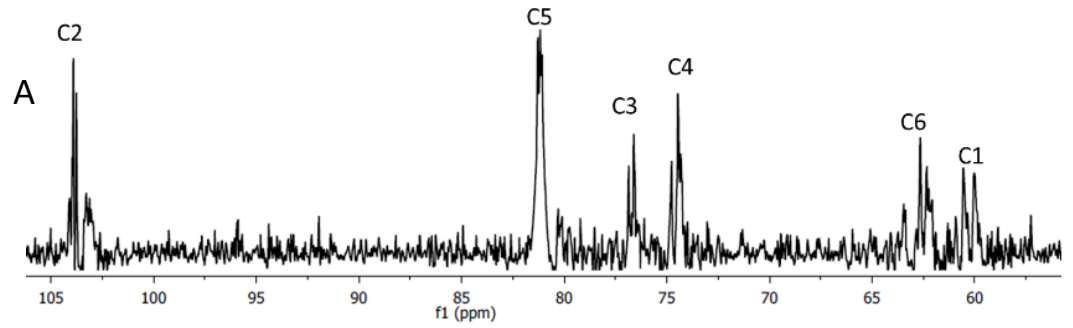



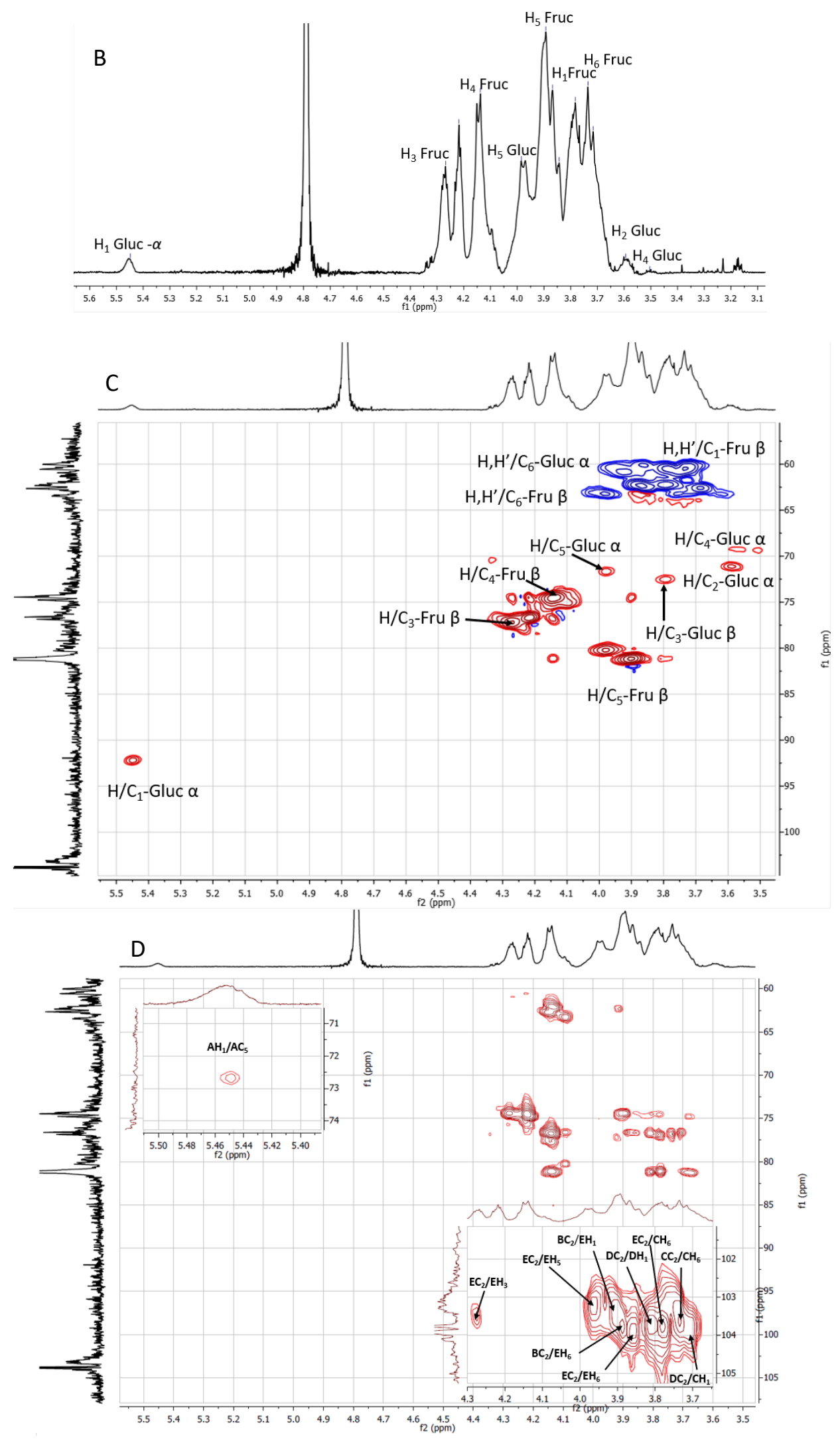

Fig. $3^{1} \mathrm{H}(A),{ }^{13} \mathrm{C}(B), H S Q C(C)$, and $H M B C(D)$ NMR spectra of OP\%US, sample obtained with optimal purity of 
Table $6{ }^{1} \mathrm{H}$ and ${ }^{13} \mathrm{C}$ NMR chemical shifts of OP\%US

\begin{tabular}{|l|l|l|l|l|l|l|}
\hline & $\mathrm{C}_{1} / \mathrm{H}_{1}$ & $\mathrm{C}_{2} / \mathrm{H}_{2}$ & $\mathrm{C}_{3} / \mathrm{H}_{3}$ & $\mathrm{C}_{4} / \mathrm{H}_{4}$ & $\mathrm{C}_{5} / \mathrm{H}_{5}$ & $\mathrm{C}_{6} / \mathrm{H}_{6}$ \\
\hline -d-Glcp-(1 $\rightarrow$ residue A & $92.15 / 5.45$ & $71.18 / 3.59$ & $72.52 / 3.79$ & $69.32 / 3.51$ & $71.67 / 3.98$ & $61.9 / 3.74$ \\
\hline$\beta$-d-Fruf- $(2 \rightarrow$ residue B & $60.55 / 3.78$ & $103.11 /-$ & $76.57 / 4.28$ & $74.42 /$ a 4.12 & $81.28 / 3.92$ & $62.65 / 3.8$ \\
\hline$\rightarrow 1,6) \beta$-d-Fruf-(2 $\rightarrow$ residue C & $57.25 / 3.71$ & $103.76 /-$ & $76.98 / 4.28^{\mathrm{a}}$ & $74.34 / 4.14$ & $80.31 / 3.88$ & $62.19 / 3.73$ \\
\hline$\rightarrow 1) \beta$-d-Fruf- $(2 \rightarrow$ residue D & $60.46 / 3.91$ & $103.93 /-$ & $76.62 / 4.27$ & $74.46 / 4.15^{\mathrm{a}}$ & $81.08 / 3.9$ & $63.37 / 3.74$ \\
\hline$\rightarrow 2) \beta$-d-Fruf- $(6 \rightarrow$ residue E & $60.04 / 3.8$ & $103.95 /-$ & $76.85 / 4.16$ a & $74.77 / 4.01$ & $80.28 / 3.98$ & $62.31 / 3.89$ \\
\hline
\end{tabular}

530

531

532

533

534

535

536

537

538

539

540

541

542

543

544

545

546

547

548

549

550

551

552

553

554

555

556

557

558

559

aUnresolved from other signals.

\subsection{Antioxidant activity}

\subsubsection{ABTS radical scavenging activity}

Fig. 4A presents the ABTS radical scavenging activity changes of OP\%US as a function of concentration, in comparison with ascorbic acid as a reference. The antioxidant activity of OP\%US increases with concentration to reach a maximum of $96.4 \%$ at $10 \mathrm{mg}$. The half maximal inhibitory concentration (IC50) is $1.28 \pm 0.13 \mathrm{mg} / \mathrm{mL}$. In the case of ascorbic acid, a very sharp increase of the antioxidant activity is observed with concentration to reach $100 \%$ at $0.1 \mathrm{mg} / \mathrm{mL}$. Luo et al. reported a maximum scavenging activity of $28.0 \%$ and $82.6 \%$ for different fractions of polysaccharides extracted from Dendrobium nobile Lindl against ABTS.+ ${ }^{+}$at $2 \mathrm{mg} / \mathrm{mL}$ [27]. Hu et al. studied the ABTS ${ }^{+}$scavenging activity of different fractions of polysaccharides extracted from Flammulina velutipes. The maximum activity was $36.7 \%, 42.4 \%$, and $61.8 \%$ at a concentration of $3 \mathrm{mg} / \mathrm{mL}$, with an IC50 value of $2.8 \mathrm{mg} / \mathrm{mL}$ [28]. Comparison with literature data suggests that OP\%US has a good scavenging activity against ABTS ${ }^{+}$.

\subsubsection{Total antioxidant capacity (TCA)}

$\mathrm{Mo}(\mathrm{VI})$ is able to combine with proteins at the metal-binding site and to cause DNA and protein damage [29], based on the reduction of Mo (VI) to Mo (V) by the formation phosphate/Mo (V) complex at acidic pH. Fig. $4 \mathrm{~B}$ presents absorbance changes of OP\%US as a function of concentration compared to BHA and $\alpha$-tocopherol, two commonly used food additives. High absorbance indicates high antioxidant activity. When the concentration increases from 0.025 to $5 \mathrm{mg} / \mathrm{mL}$, the absorption increases from 0.14 to 2.04 , from 0.02 to 0.9 and from 0.01 to 1.4 for $\alpha$-tocopherol, BHA and OP\%US respectively. It is noticed that the absorption of OP\%US becomes higher than that of BHA beyond $4 \mathrm{mg} / \mathrm{mL}$. These results suggest that OP\%US presents a remarkable TCA capacity.

\subsubsection{Metal-chelating power}


The chelating agents are reported as secondary antioxidants because they can reduce the redox potential, thereby stabilizing the oxidized form of the metal ion [30]. The ferrous chelating capacity was evaluated from absorption measurement at $562 \mathrm{~nm}$. Fig. 4C presents the chelating capacity changes of OP\%US as a function of concentration, using EDTA as a reference. The chelating activity of OP\%US gradually increases with increasing concentration, reaching a maximum of $79.7 \%$ at $10 \mathrm{mg} / \mathrm{mL}$. The IC50 of OP\%US is $3.7 \mathrm{mg} / \mathrm{mL}$. In contrast, the chelating activity of EDTA rapidly increases with concentration to reach $100 \%$ at $0.4 \mathrm{mg} / \mathrm{mL}$. Nobre et al. investigated the chelating activity of various polysaccharides. The authors obtained a maximum chelating activity of $69.9,57.8,46.1$, and $43.3 \%$ for polysaccharides extract from $C$. Prolifera, C. Sertularioides, D. Cervicornis, and D. Mertensis at $2 \mathrm{mg} / \mathrm{ml}$, respectively [31]. Qi et al. determined the chelating activity of sulfated polysaccharides extracted from Ulva pertusa. Data show that the maximum activity is $36 \%$ and $10 \%$ for highly or less sulfated polysaccharides at $2 \mathrm{mg} / \mathrm{mL}$, respectively [32]. Comparison with literature data indicates that OP\%US exhibits an acceptable $\mathrm{Fe}^{2+}$ chelating activity.

\subsection{4 $\beta$-carotene bleaching test}

Linoleic acid generates peroxide radicals that will oxidize highly unsaturated $\beta$-carotene, known as provitamin A which turns from red color to transparency. Antioxidant compounds are able to neutralize free radicals, and thus preventing the oxidation and bleaching of $\beta$-carotene [33]. This test is of major importance for human safety as it allows to determine the ability of samples to neutralize lipophilic free radicals that can easily enter human cells causing serious damage to DNA [34]. Two other samples, namely OP M (only maceration) and OP $100 \%$ US (only ultrasound), were prepared under the same conditions as OP\%US but with or without ultrasound.

Fig. 4D presents the $\beta$-carotene bleaching data of the three samples as a function of concentration in comparison with BHA as reference. The results show that the antioxidant activity of OP M, OP\%US and OP 100\%US are enhanced with increasing concentration from 0.05 to $5 \mathrm{mg} / \mathrm{mL}$. A maximum capacity of $62.5 \%, 98.1 \%$, and $82.8 \%$ are obtained at $5 \mathrm{mg} / \mathrm{mL}$ for OP M, OP\%US and OP 100\%US, respectively. BHA exhibits slightly higher activity to $\beta$ carotene bleaching than OP\%US in the 0.05 to $0.5 \mathrm{mg} / \mathrm{mL}$ concentration range. No significant difference is noticed between OP\%US and BHA in the range from 1.0 to $5.0 \mathrm{mg} / \mathrm{mL}$. The IC50 of OP M, OP\%US and OP 100\%US are $0.82 \pm 0.05,0.131 \pm 0.03$ and $0.29 \pm 0.03 \mathrm{mg} / \mathrm{mL}$, respectively. Chen et al.,Guo et al. and Shang et al. reported that ultrasound treatment enhances the antioxidant activity [18][35]]. Tang et al. observed that the antioxidant activity of polysaccharide from Cyclocarya paliurus slightly increases with US treatment from $55.5 \%$ and 
$59.0 \%$ at $500 \mu \mathrm{g} / \mathrm{mL}$ [36]. OP $100 \%$ US presents higher activity compared to OP $\mathrm{M}$, whereas the combined system presents the highest activity compared to the traditional extraction systems.
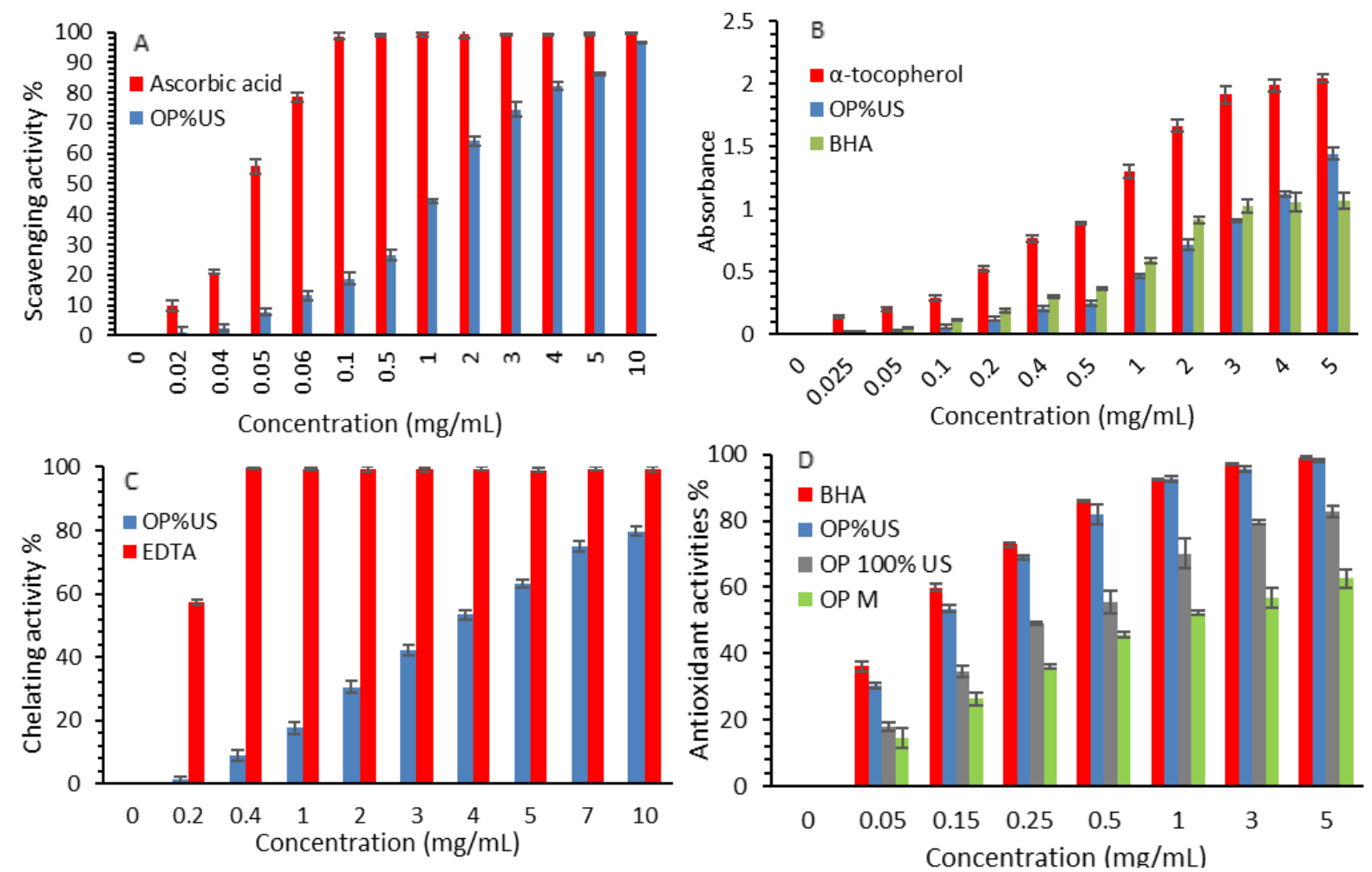

Fig. 4 Antioxidant activity of OP\%US against: ABTS radical (A), total antioxidant capacity (B), metal-chelating power (C), $\beta$-carotene bleaching (D).

598

The inhibition activity of different polysaccharides on $\beta$-carotene bleaching has been studied by many researchers. Major difference was observed between the reported values. The highest bleaching inhibition rate (82.3\%) was reported by Han et al. for polysaccharides from Plantago depressa at $3.0 \mathrm{mg} / \mathrm{mL}$ [37]. Khatua et al. reported a maximum inhibition activity of $53 \%$ for polysaccharides from Russula senecis Elicits at $0.5 \mathrm{mg} / \mathrm{ml}$, and an IC50 value of $0.49 \mathrm{mg} / \mathrm{mL}$ [38]. In contrast, a value of $13.0 \%$ and $19.3 \%$ was obtained by Rukiye et al. for polysaccharides from tragacanth gum at $20 \mathrm{mg} / \mathrm{mL}$ and from locust bean gum at $10 \mathrm{mg} / \mathrm{mL}$, respectively [39]. And Li et al. reported an IC50 of $0.14 \mathrm{mg} / \mathrm{mL}$ for polysaccharides from Lycium barbarum fruits [40]. Interestingly, in comparison with the literature, the extract obtained in the present work displays a more efficient antioxidant activity against lipophilic radicals compared to hydrophilic radicals, suggesting that it could have an anti-cancer activity [34].

\section{Conclusions}

Optimization of polysaccharides extraction was carried out for the first time via combination of two extraction methods, i.e. maceration and ultrasound treatment by using the Surface 
Response Methodology. Four influencing parameters were considered, namely total extraction

615 time, extraction temperature, ratio of water volume to raw material mass, and time percentage 616 of US treatment in the extraction process.

617 The interaction between parameters and their effects on the extraction yield and 618 polysaccharides yield were investigated. The models to predict the optimal conditions have 619 been validated by additional experiments.

620 The combination of both extraction methods improves the extraction and polysaccharides 621 yields. The combined system allows to significantly reduce the time of extraction, the 622 temperature and volume to mass ratio, and to improve the purity which is of major importance 623 for potential applications. Finally, the optimum extraction process consists of a maximum 624 duration of $20 \mathrm{~min}$ maceration and $20 \mathrm{~min}$ US treatment at relatively low temperature (ca. $62544^{\circ} \mathrm{C}$ ) using only water as solvent.

626 The extract is identified as fructo-polysaccharides the RMN analysis indicate that the OP\%US 627 possessed a backbone of $(2 \rightarrow 6)$-linked $\beta$-d-fructofuranosyl (Fruf), with $(2 \rightarrow 1)$-linked $\beta$-d-Fruf 628 branched chains, and terminated with glucose and fructose residues. It presents good 629 antioxidant activities as evidenced by ABTS radical scavenging activity, reducing activity of 630 molybdate, metal-chelating power, and $\beta$-carotene bleaching tests. The RSM allowed designing 631 an efficient process to extract polysaccharides from Ornithogalum billardieri with remarkable 632 anti-oxidant properties. Additionally, the combined system enhances the anti-lipophilic radical 633 activity of the extract. These natural compounds could be promising as alternative to synthetic 634 antioxidants like BHA for applications in agro-food and pharmaceutical industries.

\section{Conflicts of interest}

636 There are no conflicts of interest to declare.

\section{Acknowledgements}

638 M. K. Medlej benefits of Baalbeck's municipality fellowship. The work was financially supported by Platform for 639 Research and Analysis in Environmental Sciences (Lebanon) and by Institut Européen des Membranes (France).

\section{References}

641 [1] V. Labrador, P. Fernández Freire, J.M. Pérez Martín, M.J. Hazen, Cytotoxicity of 642 butylated hydroxyanisole in Vero cells, Cell Biol. Toxicol. 23 (2007) 189-199. 643 https://doi.org/10.1007/s10565-006-0153-6.

644 [2] J.K. Yan, Y.Y. Wang, H. Le Ma, Z. Bin Wang, Ultrasonic effects on the degradation 645 kinetics, preliminary characterization and antioxidant activities of polysaccharides from 
647 https://doi.org/10.1016/j.ultsonch.2015.10.005.

648 [3] R. Chen, F. Meng, Z. Liu, R. Chen, M. Zhang, Antitumor activities of different fractions of 649 polysaccharide purified from Ornithogalum caudatum Ait, Carbohydr. Polym. 80 (2010) 845650 851. https://doi.org/10.1016/j.carbpol.2009.12.042.

651 [4] Z. Persin, K. Stana-Kleinschek, T.J. Foster, J.E.G. Van Dam, C.G. Boeriu, P. Navard, 652 Challenges and opportunities in polysaccharides research and technology: The EPNOE views for the next decade in the areas of materials, food and health care, Carbohydr. Polym. 84 (2011) 22-32. https://doi.org/10.1016/j.carbpol.2010.11.044.

Z. Hrom, Ultrasonic extraction of plant materials - investigation of hemicellulose release from buckwheat hulls, Ultrason. Sonochem. 10 (2003) 127-133. https://doi.org/10.1016/S1350-4177(03)00094-4.

659 [7] Z. Ying, X. Han, J. Li, Ultrasound-assisted extraction of polysaccharides from mulberry 660 leaves, Food Chem. 127 (2011) 1273-1279. https://doi.org/10.1016/j.foodchem.2011.01.083. 661 [8] Y. Wang, A. Cornea, C. Wang, M. Guo, Effects of Ultrasound Treatment on Extraction 662 and Rheological Properties of Polysaccharides from, Molecules. 24 (2019) 939. 663 https://doi.org/10.3390/molecules24050939.

664 [9] A. Ebringerová, Z. Hromádková, An overview on the application of ultrasound in 665 extraction, separation and purification of plant polysaccharides, Cent. Eur. J. Chem. 8 (2010) 666 243-257. https://doi.org/10.2478/s11532-010-0006-2.

[10] S. Wang, X. Dong, J. Tong, Optimization of enzyme-assisted extraction of polysaccharides from alfalfa and its antioxidant activity, Int. J. Biol. Macromol. (2013) 1-10. https://doi.org/10.1016/j.ijbiomac.2013.09.029.

[11] M. DuBois, K.A. Gilles, J.K. Hamilton, P.A. Rebers, F. Smith, Colorimetric Method for Determination of Sugars and Related Substances, Anal. Chem. 28 (1956) 350-356. https://doi.org/10.1021/ac60111a017.

673 [12] D. Tang, S. Yu, Y. Ho, B. Huang, G. Tsai, H. Hsieh, Food Hydrocolloids Characterization of tea catechins-loaded nanoparticles prepared from chitosan and an edible polypeptide, Food Hydrocoll. 30 (2013) 33-41. https://doi.org/10.1016/j.foodhyd.2012.04.014.

676 [13] S.A. Mohamed, J.A. Khan, Antioxidant capacity of chewing stick miswak Salvadora 677 persica, Complement. Altern. Med. 19 (2013) 40. https://doi.org/10.1186/1472-6882-13-40.

678 [14] L. Sutharson, P.K. Kar, L.K. Nath, Shila.E.Besra, R.V.S. Joseph, Free radical scavenging 679 activity of leaves of BISCHOFIA JAVANICA BLUME AND FRAXINUS FLORIBUNDA WALLICH, 680 Pharmacologyonline. 1332 (2009) 1324-1332. 
682 Extracts for Antioxidant Activity : a Comparative Study on Three Testing Methods, Phytochem.

683 Anal. 13 (2002) 8-17. https://doi.org/10.1002/pca.611.

684 [16] A. Raza, F. Li, X. Xu, J. Tang, Optimization of ultrasonic-assisted extraction of antioxidant

685

686

687

688

689

690

691

692

693

694

695

696

697

698

699

700

701

702

703

704

705

706

707

708

709

710

711

712

713

714 polysaccharides from the stem of Trapa quadrispinosa using response surface methodology, Int. J. Biol. Macromol. 94 (2017) 335-344. https://doi.org/10.1016/j.ijbiomac.2016.10.033.

[17] P.F. Jean LEYBROS, Extraction solide-liquide.Aspects théoriques, Tech. I'ingenieur. 3 (2019) 2-21.

[18] R. Chen, Y. Li, H. Dong, Z. Liu, S. Li, S. Yang, X. Li, Optimization of ultrasonic extraction process of polysaccharides from Ornithogalum Caudatum Ait and evaluation of its biological $\begin{array}{lllll}\text { activities, } & \text { Ultrason. } & \text { Sonochem. } & 19 & \text { (2012) }\end{array}$ https://doi.org/10.1016/j.ultsonch.2012.03.008.

[19] Q. Chen, S.Z. Zhang, H.Z. Ying, X.Y. Dai, X.X. Li, C.H. Yu, H.C. Ye, Chemical characterization and immunostimulatory effects of a polysaccharide from Polygoni Multiflori Radix Praeparata in cyclophosphamide-induced anemic mice, Carbohydr. Polym. 88 (2012) 1476-1482. https://doi.org/10.1016/j.carbpol.2012.02.055.

[20] X. Wang, R. Sun, J. Zhang, Y. Chen, N. Liu, Structure and antioxidant activity of polysaccharide POJ-U1a extracted by ultrasound from Ophiopogon japonicus, Fitoterapia. 83 (2012) 1576-1584. https://doi.org/10.1016/j.fitote.2012.09.005.

[21] K. Zhong, Q. Zhang, L. Tong, L. Liu, X. Zhou, S. Zhou, Molecular weight degradation and rheological properties of schizophyllan under ultrasonic treatment, Ultrason. Sonochem. 23 (2015) 75-80. https://doi.org/10.1016/j.ultsonch.2014.09.008.

[22] G.L. Ailiesei, M. Ciobanu, M. Balan, C. Stavarache, L. Barbes, A. Nicolescu, C. Deleanu, NMR detected metabolites in complex natural fluids. Quinic acid in apple juice, Ovidius Univ. Ann. Chem. 26 (2015) 51-56. https://doi.org/10.2478/auoc-2015-0009.

[23] J. Liu, A.L. Waterhouse, N.J. Chatterton, Proton and carbon NMR chemical-shift assignments for [ $\beta$-d-Fruf- $(2 \rightarrow 1)] 3-(2 \leftrightarrow 1)-\alpha$-d-Glcp (nystose) and [ $\beta$-d-Fruf- $(2 \rightarrow 1)] 4-(2 \leftrightarrow$ 1)- $\alpha$-d-Glcp (1,1,1-kestopentaose) from two-dimensional NMR spectral measurements, Carbohydr. Res. 245 (1993) 11-19. https://doi.org/10.1016/0008-6215(93)80056-K.

[24] C. Wang, D. Hua, C. Yan, Structural characterization and antioxidant activities of a novel fructan from Achyranthes bidentata Blume, a famous medicinal plant in China, Ind. Crops Prod. 70 (2015) 427-434. https://doi.org/10.1016/j.indcrop.2015.03.051.

[25] L. Zhang, N. Reddy, C. Soo Khoo, S. Rao Koyyalamudi, C.E. Jones, Antioxidant and Immunomodulatory Activities and Structural Characterization of Polysaccharides Isolated from 

https://doi.org/10.5567/pharmacologia.2018.157.168. [26] J. Chen, K.L. Cheong, Z. Song, Y. Shi, X. Huang, Structure and protective effect on UVBinduced keratinocyte damage of fructan from white garlic, Carbohydr. Polym. 92 (2013) 200205. https://doi.org/10.1016/j.carbpol.2012.09.068.

[27] A. Luo, X. He, S. Zhou, Y. Fan, A. Luo, Z. Chun, Purification, composition analysis and antioxidant activity of the polysaccharides from Dendrobium nobile Lindl ., Carbohydr. Polym. 79 (2010) 1014-1019. https://doi.org/10.1016/j.carbpol.2009.10.033.

[28] L. Cell, Characterization and Antioxidant Activities of Yellow Strain Flammulina velutipes ( Jinhua Mushroom ) Polysaccharides and Their E ff ects on ROS Content in, Antioxidants. 8 (2019) 1-15. https://doi.org/10.3390/antiox8080298.

[29] William Pratt, Transformation of Glucocorticoid and Progesterone Receptors to the DNA-Binding State, J. Cell. Biochem. 68 (1987) 51-68.

[30] K. Pavithra, S. Vadivukkarasi, Evaluation of free radical scavenging activity of various extracts of leaves from Kedrostis foetidissima ( Jacq .) Cogn ., Food Sci. Hum. Wellness. 4 (2015) 42-46. https://doi.org/10.1016/j.fshw.2015.02.001.

[31] L.S. Costa, L.T.D.B. Nobre, G.P. Fidelis, S.L. Cordeiro, R.M. Oliveira, D.A. Sabry, R.B.G. Ca, M.S.S.P. Costa, E.H.C. Farias, E.L. Leite, H.A.O. Rocha, Biological activities of sulfated polysaccharides from tropical seaweeds, Biomed. Pharmacother. 64 (2010) 21-28. https://doi.org/10.1016/j.biopha.2009.03.005.

[32] H. Qi, Q. Zhang, T. Zhao, R. Chen, Q. Huimin, Z. Quanbin, Z. Tingting, C. Rong, Gz. Hon, N. Xizhen, L. Zhien, Antioxidant activity of different sulfate content derivatives of polysaccharide extracted from Ulva pertusa (Chlorophyta) in vitro, Int. J. Biol. Macromol. 37 (2005) 195-199. https://doi.org/10.1016/j.ijbiomac.2005.10.008.

L. Unten, M. Koketsu, M. Kim, Antidiscoloring Activity of Green Tea Polyphenols on Carotene, J. Agric. Food Chem. 8561 (2012) 1-3.

[34] G. Amandine, Plantes médicinales et antioxydants, TOULOUSE III PAUL SABATIER, 2016.

[35] X. Guo, X. Shang, X. Zhou, B. Zhao, J. Zhang, Ultrasound-assisted extraction of polysaccharides from Rhododendron aganniphum: Antioxidant activity and rheological https://doi.org/10.1016/j.ultsonch.2017.03.021.

[36] W. Tang, L. Lin, J. Xie, Z. Wang, H. Wang, Y. Dong, M. Shen, M. Xie, Effect of ultrasonic treatment on the physicochemical properties and antioxidant activities of polysaccharide from

Carbohydr. Polym.

151

(2016)

$305-312$. https://doi.org/10.1016/j.carbpol.2016.05.078. 
750 [37] N. Han, L. Wang, Z. Song, J. Lin, C. Ye, Z. Liu, J. Yin, International Journal of Biological 751 Macromolecules Optimization and antioxidant activity of polysaccharides from Plantago 753 https://doi.org/10.1016/j.ijbiomac.2016.09.028.

754 [38] S. Khatua, K. Acharya, Water Soluble Antioxidative Crude Polysaccharide From Russula 755 senecis Elicits TLR Modulated NF- $\mathrm{k}$ B Signaling Pathway and Pro-inflammatory Response in 756 Murine Macrophages, Front. Pharmacol. 9 (2018) 1-11. 757 https://doi.org/10.3389/fphar.2018.00985.

758 [39] R. Boran, A. Ugur, N. Sarac, Investigation of Hyaluronidase, Collagenase and Elastase 759 Inhibitory Potentials and Comparative Evaluation of the Antimicrobial, Antioxidant and 760 Homeostatic Activities of Two Natural Polysaccharides, J. Nat. Appl. Sci. 22 (2018) 1182-1189. 761 https://doi.org/10.19113/sdufenbed.471994.

762 [40] X.M. Li, X.L. Li, A.G. Zhou, POLYMER Evaluation of antioxidant activity of the 763 polysaccharides extracted from Lycium barbarum fruits in vitro, Eur. Polym. J. 43 (2007) 488764 497. https://doi.org/10.1016/j.eurpolymj.2006.10.025. 